\title{
Application of thermovision method in analysing metallurgical processes
}

\author{
by W. Wittchen, M. Niesler, M. Borecki and B. Zdonek
}

Institute For Ferrous Metallurgy in Gliwice, Poland

\section{Abstract}

There were presented possibilities and examples of the use of infrared technique in the iron and steel industry as a method of temperature analysis on the surface of the object.

There were shown several practical examples of the use of infrared cam as a tool, which can make us able to control technical state of the devices and production cycle.

There were emphasised non-invasive character of researches, which allows us to take measurements without disturbing production cycle during the normal work of the device.

\section{Introduction}

In the iron and steel industry, processes of transferring a large amount of heat are realised. These processes usually are performed in the huge devices and lot of operational and conservational problems is connected with temperature.

In the control of the state of these devices thermovision can play important role, which can be used in the iron industry as a non-invasive method of analysing thermal state of the devices as well as control of technological procedures. These investigations can influence on keeping devices in good condition and improvement of the technological procedures [1-5].

Main trends of the use of infrared technique in the iron and steel industry are as follows:

- Determine technical state of the devices

(furnaces, pouring ladles, pipelines)

- Investigation of the metallurgical processes

(blast furnaces, steelworks, plastic deformation, heat treatment)

\section{Use of thermovision in the iron and steel making}

\section{Analysis of the state of the devices}

Infrared cam gives us possibility to make fast analysis of the state of the devices during its normal work. This analysis provides us basic characteristics of the working devices and fast prevention of the deterioration of their technical condition as well as increasing of frequency of the use of the devices [1-3].

Examples are as follows:

- Detection of defects in refractory lined hot metal containers

- Detection of the heat losses of reheating furnaces

- Detection of dirt accumulations in overhead gas mains

Examples listed above are described below in details.

In the iron industry, state of the fire-resistant lining of the basic metallurgical devices like furnaces and pouring ladles is very important issue. Fire-resistant lining of furnaces is exposured to destructively effect of heat, chemical and mechanical factors, which causes gradual using up. Commonly, destruction of that lining is unnoticeable from outside and is noticed only in critical phase. Knowledge about thickness of the fire-resistant lining decides about possibility of preventing breakdowns and selection of optimal time of work of the devices between repairs. Use of thermovision method in periodical investigations of the devices allows to illustrate temperature on the surface of the investigated object and achieve fast information about thermal condition. Infrared cam make us able to detect critical points exposured to destructions by localization of the points possessing highest temperature. These investigations are helpful in preventing breakdowns and in planning repairs optimally and in advance. Example of application of the furnace during sudden breakdown is shown on the Fig. 1. This breakdown was revealed by very high temperature on the surface of investigated object. Immediately cooling of the armour plating allowed to control critical state, what was shown on the Fig. 2. 


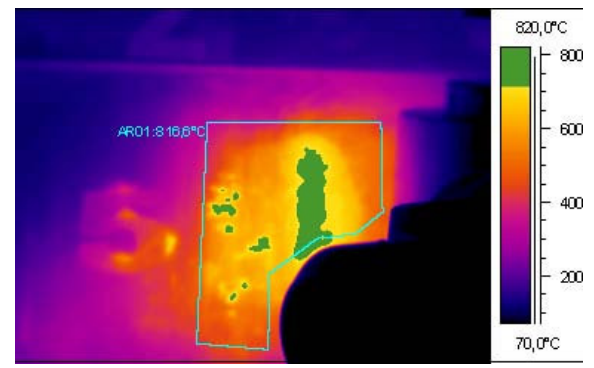

Fig. 1. Thermal image illustrating temperature of the surface of he armour plating at the beginning of the breakdown (area max: $815^{\circ} \mathrm{C}$ ).

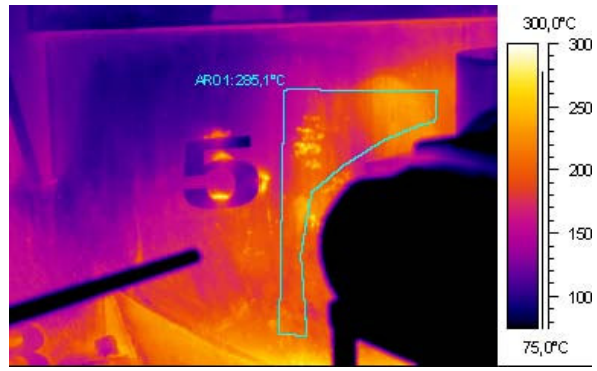

Fig. 2. Thermal image illustrating temperature on the surface of he armour plating during controlling the critical state (area max: $\sim 285^{\circ} \mathrm{C}$ ).

Infrared cam can be used in detection of the heat losses of the reheating furnaces by detection points with the most intensive heat transfers. Detection of these points can eliminate heat looses of the furnaces.

Another example of diagnosis of the devices conditions is detection of dirt accumulations in overhead gas mains. In the pipelines draining and supplying gases large amount of dusts is accumulated. This dust can be reason for serious problems connected with reducing flow, excessive decreasing of pressure or overloading of the construction of the pipelines, what can cause breakdown. Gases flowing in the pipelines are usually strongly heated up, so places where dusts are accumulated can be easily detected with using infrared cam, because they have different temperature than rest of the pipelines. Periodical thermovision investigations allows to make continuous observation of the change of the dirt level. With having such knowledge it is possible to prevent breakdown. Case of the temporary disabling production process as a result of break down of the pipelines with accumulated dust inside is known [1].

\section{Control of technological processes and assistance for the research processes}

Thermovision technique can be widely used in verifying the propriety of the metallurgical, technological processes. It is connected with the processes where problem of heat exchange is present (heating, cooling) and crucial parameter is regularity of the temperature of the products.

Example are as follows:

- remote detecting of the slag

- analysis of the processes of the continuous steel casting

- control of the processes of the plastic deformation

- and other applications.

Examples listed above are described below in details.

In the metallurgical process important issue is to prevent getting the slag in the pouring ladle, because of its bad influence on steel proprieties. We can observe presence of the slag in stream of liquid metal by measurement of the energy radiated from steel and slag in infrared waves. Use of this method in connection with appropriate system of closing tapping hole, can prevent getting the slag in the pouring ladle, what bring concrete metallurgical effects like improvement of the quality of the steel and reducing costs of the production. Exemplary application is presented on the Fig. 3. and Fig. 4., where is thermal image illustrating liquid metal flowing out from the tapping hole (Fig. 3.) and appearance of the slag (Fig. 4.). In the thermal image we can observe appearance of the slag in metal with using various characteristics of the radiation of the liquid steel and slag. In practice, on the screen of the infrared cam we can observe change of the colour of the stream which flows out in the moment of appearance of the slag in the tapping hole. Installation of the proper infrared system in the steelworks can be an alternative for traditional methods of detecting slag. 


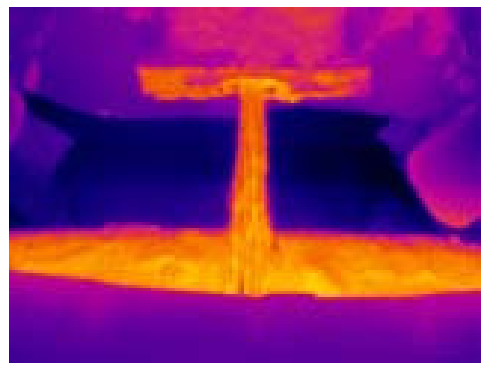

Fig. 3. Thermal image illustrating liquid metal flowing out from the tapping hole.

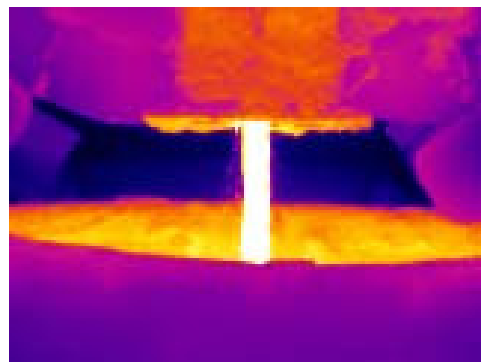

Fig. 4. Thermal image illustrating appearance of the slag in the tapping hole.

Another example is the control of the process of the continuous steel casting, where ingots can be analysed in continuous way. This method allows to check propriety of the cooling process, where irregular temperature of the surface of the ingot can be caused by improper method of cooling. In consequence, cracks can appear.

Infrared technique plays important role in the control of the plastic deformation (milling, rolling or making pipelines), where for guarantee proper production process keeping temperature in strictly defined narrow range is obligatory. In such cases, installation of the stationary infrared systems on the production lines is deliberated. We can see examples of the using such systems in the rolling mills.

In addition, infrared can be used in many various applications. For example: control of the furnaces, analysis of the cooling down process, optimization of heat treatment etc. Example of the control of cooling down process is shown on the Fig. 5. Line profile which characterizes cooling down process is show on the Fig. 6.

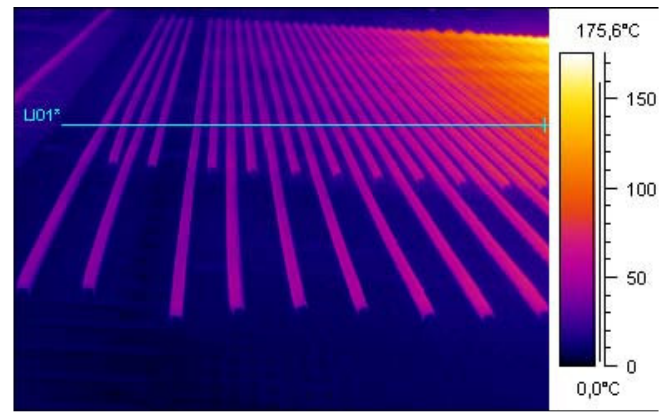

Fig. 5. Thermal image illustrating temperature of the surface of cooled down elements.

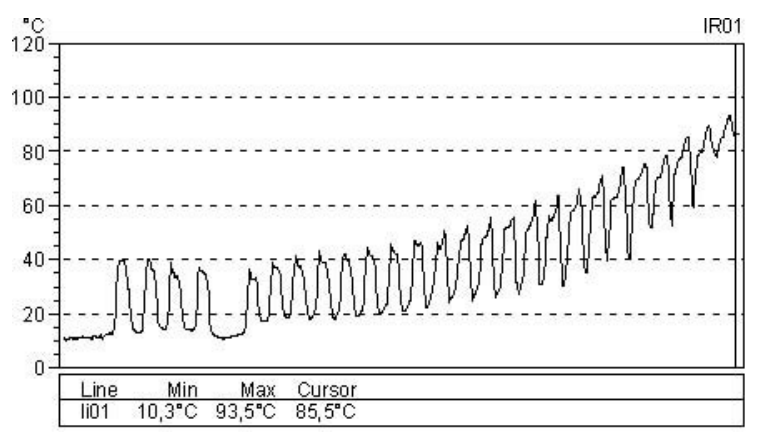

Fig. 6. Thermal image illustrating line profile characterising cooling down process. 
In this case, use of thermovision method allows to control process of cooling down and investigate effectiveness of the work of cold storage. Having such knowledge, we can optimize work conditions of the cold storage and type of the cooled down elements.

\section{Conclusion}

Thermovision technique can be widely used in the iron and steel industry. Basing on obtained results of investigations and their analysis we can estimate technical state of the devices, control production processes and verify technological procedures. With using infrared cam and appropriate software used for analysis of thermal images, we have possibility to detect in concrete installation area possessing highest temperature and measure the temperature in real-time.

It should be emphasised that investigations are made in non-invasive way, without disturbing production process. Commonly, obtaining such information with using methods different than thermovision is very hard and often impossible.

\section{REFERENCES}

[1] Wittchen W.: Zastosowanie badan termowizyjnych we współczesnej technice pomiarowej, Sprawozdanie IMG, Nr S-00211/BS, 1998, (nieopublikowane)

[2] Wittchen W., Borecki M., Mazur A.: Zastosowanie badan termowizyjnych do oceny procesów produkcyjnych w przemysle hutniczym, Hutnik - Wiadomosci Hutnicze, 2000, s. 115-120

[3] Green L.: Condition monitoring - its impact on plant performance at British Steel Scunthorope Works, Ironmaking and Steelmaking, Nr 5, 1990, s. 355-362

[4] Wittchen W., Borecki M.: Wykonanie badan termowizyjnych rozkładu temperature strumienia stali podczas spustu wraz z interpretacja wyników, Sprawozdanie IMG, Nr B-01141/BS, 2002, (nieopublikowane)

[5] Goldstein D.A., Sharan A., Stofanak J.A.: Infrared Imaging for BOF Slag Detection, Iron a. Steelmaker, t. 27 , Nr 7, 2000, s.31-38 